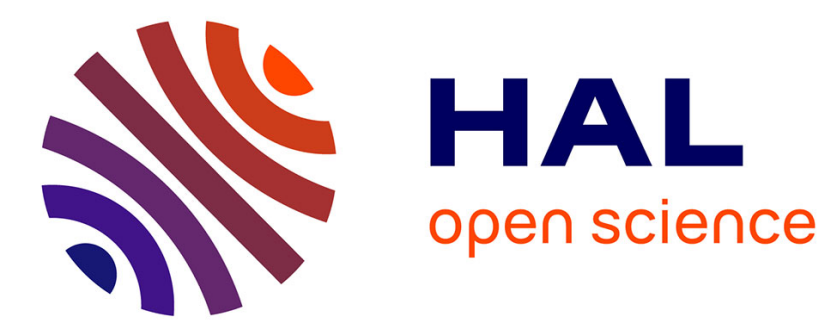

\title{
Size Dependent Magnetic Properties of Zinc Ferrite Fine Particles
}

\author{
M. Yokoyama, E. Ohta, T. Sato, T. Komaba
}

\section{To cite this version:}

M. Yokoyama, E. Ohta, T. Sato, T. Komaba. Size Dependent Magnetic Properties of Zinc

Ferrite Fine Particles. Journal de Physique IV Proceedings, 1997, 07 (C1), pp.C1-521-C1-522. 10.1051/jp4:19971212 . jpa-00254864

\section{HAL Id: jpa-00254864 https://hal.science/jpa-00254864}

Submitted on 1 Jan 1997

HAL is a multi-disciplinary open access archive for the deposit and dissemination of scientific research documents, whether they are published or not. The documents may come from teaching and research institutions in France or abroad, or from public or private research centers.
L'archive ouverte pluridisciplinaire HAL, est destinée au dépôt et à la diffusion de documents scientifiques de niveau recherche, publiés ou non, émanant des établissements d'enseignement et de recherche français ou étrangers, des laboratoires publics ou privés. 


\title{
Size Dependent Magnetic Properties of Zinc Ferrite Fine Particles
}

\author{
M. Yokoyama, E. Ohta, T. Sato*, T. Komaba** and T. Sato** \\ Department of Materials Science, Faculty of Science and Technology, Keio University, 3-14-1 Hiyoshi, \\ Kohoku-ku, Yokohama, Kanagawa 223, Japan \\ * Department of Instrumentation Engineering, Faculty of Science and Technology, Keio University, 3-14- \\ 1 Hiyoshi, Kohoku-ku, Yokohama, Kanagawa 223, Japan \\ ** Department of Electronics, Faculty of Engineering, Tokyo Engineering University, 1404-1 Katakura, \\ Hachioji, Tokyo 192, Japan
}

\begin{abstract}
We investigate the particle size dependence of magnetic properties of $\mathrm{ZnFe}_{2} \mathrm{O}_{4}$ fine particles. The fine particles with different particle sizes were obtained by heating the coprecipitated powder. The magnetization slowly increases with decreasing the particle size, and drastically in the particles with diameter $<30 \mathrm{~nm}$. The size dependent magnetization shows maximum around $\sim 8 \mathrm{~nm}$ in diameter. The Curie temperature al so increases with decreasing the particle size. Such changes in the magnetization and Curie temperature can be explained in terms of the distribution of $\mathrm{Fe}^{3+}$ ions dependent on the particle size.
\end{abstract}

\section{INTRODUCTION}

Zinc ferrite $\left(\mathrm{ZnFe}_{2} \mathrm{O}_{4}\right)$ has an almost normal spinel structure with a tetrahedral A-site occupied by $\mathrm{Zn}^{2+}$ ions and an octahedral B-site by $\mathrm{Fe}^{3+}$ ions, and exhibits an anomalous antiferromagnetic behavior with a Néel temperature of about $9 \mathrm{~K}$ [1]. Lotgering[2] has suggested that a small number of $\mathrm{Fe}^{3+}$ ions occupy the tetrahedral $\mathrm{A}$-site, and the clusters consisting of $\mathrm{Fe}^{3+}$ ions are formed at the octahedral B-site through a coupling by the A-B interaction. Ligenza[3] has found that $4 \%$ of the A-sites are occupied by Fe ${ }^{3+}$ ions.

Ultra-fine $\mathrm{ZnFe}_{2} \mathrm{O}_{4}$ particles prepared by the coprecipitation method have remarkably larger magnetization than the bulk materials by the ceramic method. [4] The enhanced magnetization would originate from the magnetic cluster formation caused by the deviation of cation distribution from the normal spinel structure. We expect that the magnetic clusters formation develop with decreasing the particle size. Thus, we investigate the size dependence of magnetic properties of $\mathrm{ZnFe}_{2} \mathrm{O}_{4}$ fine particles.

\section{EXPERIMENTAL PROCEDURE}

Ultra-fine $\mathrm{ZnFe}_{2} \mathrm{O}_{4}$ particles were prepared by the coprecipitation method. [4] The fine particles with different particle sizes were obtained by heating the coprecipitated powder. We evaluated the average particle size from the full width at half maximum of X-ray diffaction (XRD) pattern line (311) by using Scherner's formula. The magnetic measurements were performed using a vibrating sample magnetometer (VSM) and a superconducting quantum interference device (SQUD) magnetometer. The size dependence of magnetization in a magnetic field of $15 \mathrm{kOe}$ can be evaluated at $77 \mathrm{~K}$ and $300 \mathrm{~K}$. The temperature dependent magnetization was measured in a magnetic field of $10 \mathrm{kOe}$ at temperatures below $773 \mathrm{~K}$.

\section{RESULTS AND DISCUSSION}

The XRD patterns of the coprecipitated powder of $\mathrm{ZnFe}_{2} \mathrm{O}_{4}$ and the specimens obtained by heating it indicate the increasing in average particle size with increasing the annealing temperature. Size dependent magnetizations of $\mathrm{ZnFe}_{2} \mathrm{O}_{4}$ fine particles at 300 $\mathrm{K}$ and $77 \mathrm{~K}$ are shown in Fig. 1. The magnetization slowly increases with decreasing the particle size, and drastically in the particles with diameter $<30 \mathrm{~nm}$, and then, shows a maximum around $\sim 8 \mathrm{~nm}$ in diameter. 


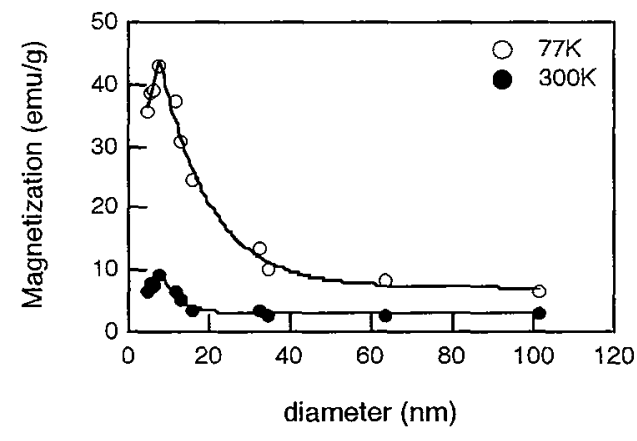

Figure 1: Size dependent magnetization of $\mathrm{ZnFe}_{2} \mathrm{O}_{4}$ fine particles in a magnetic field of $15 \mathrm{kOe}$ at $300 \mathrm{~K}$ and $77 \mathrm{~K}$. The size dependence of the fine particles shows maximum around $\sim 8 \mathrm{~nm}$ in diameter.

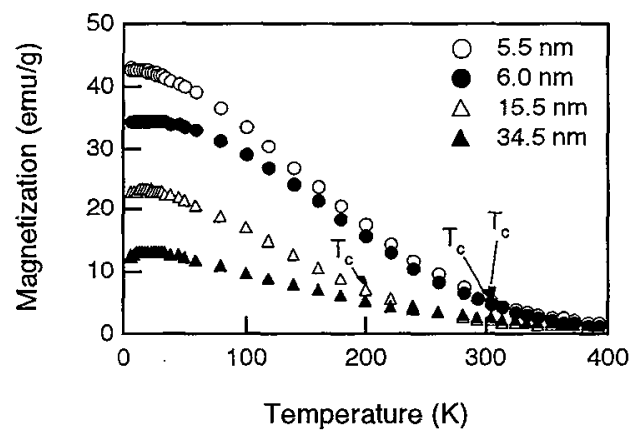

Figure 2: Temperature dependence of magnetization of $\mathrm{ZnFe}_{2} \mathrm{O}_{4}$ fine particles with different particle sizes in a magnetic field of $10 \mathrm{kOe}$. The Curie temperature $\mathrm{T}_{\mathrm{c}}$ of $\mathrm{ZnFe} \mathrm{F}_{2} \mathrm{O}_{4}$ fine particles with the smaller particle size is larger than that with the larger particle size.

Tenperature dependence of magnetization of $\mathrm{ZnFe}_{2} \mathrm{O}_{4}$ fine particles with different particle sizes measured in a magnetic field of $10 \mathrm{kOe}$ are shown in Fig. 2. The magnetizations of $\mathrm{ZnFe}_{2} \mathrm{O}_{4}$ fine paticles with 5.5 and $6.0 \mathrm{~nm}$ monotonically decrease with increasing temperature, while the magnetizations of $\mathrm{ZnFe}_{2} \mathrm{O}_{4}$ fine particles with 15.5 and $34.5 \mathrm{~nm}$ show maxima at $19 \mathrm{~K}$ and $20 \mathrm{~K}$, respectively. The Curie temperatures, which are determined on the basis of the square magnetization[5], are 304K, 303K, and 197K in $\mathrm{ZnFe}_{2} \mathrm{O}_{4}$ fine particles with $5.5,6.0$, and $15.5 \mathrm{~nm}$, respectively. We could not determine the Curie temperature for the sample with $34.5 \mathrm{~nm}$, because of non-linearity of the square magnetization. The Curie temperature of $\mathrm{ZnFe}_{2} \mathrm{O}_{4}$ fine particles tends to increase with decreasing the particle size.

The neutron diffraction study of ultra-fine $\mathrm{ZnFe}_{2} \mathrm{O}_{4}$ particles[6] indicated that occupancy of $\mathrm{Fe}^{3+}$ ions at the A-sites is 0.142 and 0.108 in the fine particles obtained by heating the coprecipitated powder of $\mathrm{ZnFe}_{2} \mathrm{O}_{4}$ at $500^{\circ} \mathrm{C}$ and $700^{\circ} \mathrm{C}$, respectively. This suggests the increase in the number of the magnetic clusters consisting of the $\mathrm{Fe}^{3+}$ ions with decreasing of particle size. Such change in the distribution of $\mathrm{Fe}^{3+}$ ions may result in the increase in the number of the magnetic clusters consisting of the $\mathrm{Fe}^{3+}$ ions with decreasing the particle size. This picture is consistent with the size dependent magnetization of the $\mathrm{ZnFe}_{2} \mathrm{O}_{4}$ fine particles with diameter $>8 \mathrm{~nm}$. The temperature dependent magnetization of such a larger particle retains some trace of antiferromagnetism in the bulk sample, i.e., the characteristic peak and the low Curie temperature, because of the small number of magnetic clusters. On the other hand, the magnetization of sample with diameter $<8 \mathrm{~nm}$ shows the size dependence opposite to that of the larger samples, although the temperature dependent magnetization of smaller particles is characterized by the ferromagnetic feature, i.e., the monotonical thermal evolution and the significantly high Curie temperature. Such behavior can be explained in terms of the increase in the magnetic clusters and the strengthened antiferromagnetic interaction between $\mathrm{Fe}^{3+}$ ions at the $\mathrm{A}$ and $\mathrm{B}$ sites accompanied by the increase in $\mathrm{Fe}^{3+}$ ions occupying the $\mathrm{A}$ sites with decreasing the particle size.

In conclusion, the magnetic behavior of $\mathrm{ZnFe}_{2} \mathrm{O}_{4}$ fine particles as a function of the particle size can be explained on the basis of the distribution of $\mathrm{Fe}^{3+}$ ions.

\section{References}

[1] J. M. Hastings and L. M. Corliss, Phys. Rev. 102 (1956) 1460-1463.

[2] F. K. Lotgering, J. Phys. Chem. Solids 27 (1966) 139-145.

[3] S. Ligenza, Phys. Stat. Sol. (b) 75 (1976) 315-326.

[4] T. Sato, K. Haneda, T. Iijima, and M. Seki, Proc. 6th Intern. Conf. Ferrites, (1992) 984-987.

[5] J. S. Kouvel, and D. S. Rodbell, Phys. Rev. Letters 18 (1967) 215-218.

[6] T. Kamiyama, K. Haneda, T. Sato, S. Ikeda, and H. Asano, Solid State Comm. 81 (1992) 563-566. 